\title{
Process Innovation: Redesigning an Enterprise Backbone System
}

\author{
Joachim Van den Bergh and Stijn Viaene \\ Joachim. VandenBergh@vlerick.com
}

\begin{abstract}
This case study covers the story of a process reengineering effort at Belgacom Mobile, the largest Belgian mobile telecommunications operator. It describes how a smart combination of theoretical concepts can lead to process innovation, and product innovation. The process innovation effort consisted of a large automation pillar and the rebuilding of the enterprise backbone system SPOMS. Architectural principles were applied to allow the redesigned process to be flexible and capable of dealing with newly emerging SIM card types and technological advances. The sub-processes will be orchestrated by the process owner who controls the entire process from a process dashboard. This case shows the potential benefits of Business Process Management (BPM), ITenabled innovation and Product Factory. The redesigned SIM card ordering process thus provides a sustainable answer to the ever shortening life-cycle of products and technologies, SIM cards in particular, and the call for process flexibility in fast changing environments.

The contribution of this project to the general understanding IT-enabled innovation lies in the innovative approach. Namely, product and process were separated from each other by means of Production Process ID creation. The redesigned SIM card ordering process thus provides a sustainable answer to the ever shortening life-cycle of products and technologies, SIM cards in particular. The redesigned sub-processes are orchestrated by the process owner who controls the entire process from a process dashboard. In terms of performance improvement, the project resulted in (1) increased process flexibility (2) and consistency, (3) dramatically shortened lead-times and (4) better control over the process.
\end{abstract}

Keywords: IT-enabled innovation, Business Process Management, Flexibility, Process Design, Process Innovation, Enterprise systems.

\section{Introduction}

In order to survive and thrive in a highly competitive business environment, organizations need to be in control of their business processes. Moreover, organizations that find themselves in a sector with galloping technological developments experience the necessity of flexible processes characterized by a high degree of product independence [1]. Belgacom Mobile, market leader in the Belgian mobile telecommunications market, finds itself in such a position and is continuously pressured by the smaller challengers in the market. Furthermore, the mobile 
telecommunications sector is known to develop at a rapid pace, driven by technological advances. It is, therefore, crucial for Belgacom Mobile to be capable of managing and optimizing its business processes and on top of that keeping them adaptable to emerging technologies with the support of a reliable enterprise IT system.

The severe fight for the customer due to the market situation results in large promotional marketing campaigns, for example inclusion of free SIM cards with popular magazines. These campaigns are typically dependent on temporary trends and needed quick response from the back office processes producing and supplying the SIM cards. Simultaneously new types of SIM cards are being introduced as a result of technological advances, requiring to be embedded in the existing process structure.

Due to these circumstances the SIM card ordering process at Belgacom Mobile, a core business process for the company, was under increasing pressure. In 2006 the supply chain management team realised that the process and its supporting technology SPOMS (SIM card Purchasing Order Management System) needed a thorough reengineering. Most of the expertise on the old tool had left the company and furthermore it was starting to become clear that the process was not as flexible and agile as required to react on requests from the marketing department. Lastly, the process as it was, posed an impediment for product innovation because it needed reworking for each and every new type of SIM card that was being introduced. Some decisive action to set this situation right was necessary. After several rounds of proposals an innovative solution came to light to automate and simplify the SIM card order process.

As stated in the official business case document the objective was to "reengineer the current SIM card order management process to make the process future-proof, efficient and flexible". Whereas at first, they had a mere automation of the existing process in mind - it was very labour intensive - over time the mindset shifted towards an approach that emphasised both process reengineering and automation. Based on the business case developed by the supply chain team, stressing the numerous benefits of reengineering, and the risk associated with not doing the project, the project received a 'MUST DO' label from the review committee. Thus the project became a high strategic priority and gained access to the necessary resources.

This case study is specifically intended to formulate an empirically evidenced answer to these research questions, validating the existing body of knowledge and theory on IT-enabled process innovation and enterprise systems: How does IT support enterprise processes in turbulent environments? Does a combination of BPM and SOA truly deliver superior business results? What are the key success factors in an IT-enabled process innovation effort?

The originality of the final project set-up presents this case as the perfect example for showcasing IT-enabled process innovation. First, relevant concepts of BPM, ITenabled innovation, architecture and process-specific terms are situated. Next, the context, business case and set-up for the project are described. Subsequently, the project's main features and particularities are outlined. To conclude, the results of the Belgacom Mobile project are presented and the learning points and contributions are explained. 


\section{Theoretical Background}

\subsection{Processes and Flexibility: An Architectural Approach}

Flexibility is generally defined as the ability to adapt to different circumstances. It is one of the main goals of process management since flexible processes are appreciated assets to deal with changing market demands. IT infrastructure needs to allow such flexibility in business processes. Process management systems are according to Weske [2] narrowing the gap between business objectives and the technology that is there to help achieving those goals. Notwithstanding the fact that IT systems have shown to be capable of enhancing process flexibility there are mixed feelings towards their role in all this. Especially the widespread implementations of diverse ERP systems have led to discussion. One could argue that adapting processes in such a way that they would fit the prescribed ERP software reference processes is hardly a practice that promotes process flexibility. If an organisation manages its processes well, they can be considered as a source of competitive advantage. On the other hand there is a tendency towards the use of industry best practices and reference models, turning certain processes more and more into a commodity. Working on process innovation expectedly results in superior business processes that differentiate an organisation from its competitors.

Process flexibility comes with two major requirements as stated by Stohr and zür Mühlen [3]: "First, there must be a capability to develop new processes and change existing processes rapidly and inexpensively, and secondly process work must be flexible within the scope of a given process design." The former implies that (new) processes must be designed in such a way that they can be deployed rapidly. Several enterprise process management systems now provide the ability to transform process models into executable processes. The underlying technology is crucial since it must allow for interoperability with other internal and external IT applications. Thus, new processes can easily connect to other systems and reuse parts of existing processes as services that can be invoked.

With regard to the SPOMS project, both the Supply Chain Manager and the external consultants involved in the project agreed that an architectural approach was best suited for this particular project. Specifically, Service Oriented Architecture (SOA) is said to bring various advantages to business processes [4, 5]. Numerous blogs, vendor reports and white papers have spread the belief that SOA and BPM are two sides of the same coin and that both approaches deliver the best results when combined $[6,7,8]$.

SOA was defined as a "component model that interrelates the different functional units of an application, called 'services', through well-defined interfaces and contracts between these services. The interface is defined in a neutral manner that should be independent of the hardware platform, the operating system, and the programming language in which the service is implemented" [9]. Loose coupling and reusability of services are the cornerstones of the interest in SOA as a means to make business processes more agile, a condition for sustainable success in today's business environments. Both legacy systems and newly developed applications can be 
formulated as a set of services as well as external systems [10]. Each business process can call on these services when needed. SOA requires the set-up of a new architectural layer of abstraction - at the service level - between processes and systems. Loose coupling stands for the fact that the service requester should not be aware of the structure that underpins the requested service [11]. A recent literature study showed that SOA literature has exponentially increased in the last few years [12]. In another study Becker et al. [13] concluded that SOA adoption is still in its early phase.

Turbulent business environments call for adequate approaches to provide robust IT support for business processes. El Sawy and Pavlou [14] stated that "using an SOA and web services is an effective way of conserving IT investments because it removes the need for massive integration and re-integration expenditures when requirements change". The flexibility of modular business processes and supporting IT systems lies in the quick adaptation capabilities when the business environment changes, and in this way affects the business processes. However, SOA implementation involves several challenges. First of all, identifying and defining services could pose a problem to organizations. Another challenge of SOA is the involvement of the business in the process [15]. Therefore alignment between business and ICT is a key success factor for SOA implementation. Finally, SOA should never be a strategy in its own right, but should be a decision to support the organizational strategy [16].

Business Process Management (BPM) is an essential capability for many organizations. It provides a horizontal view of an organization's core business processes and the organization's capability of managing, improving and controlling these processes [17]. Zairi [18] defines BPM as "a structured approach to analyses and continually improve fundamental activities such as manufacturing, marketing, communications and other major elements of a company's operation." Over the past years, the potential benefits of BPM have repeatedly been addressed in management literature. Among the reported benefits we note: increased process efficiency [19], higher speed-to-market, cost effectiveness, enterprise process coordination [17], and strategic alignment $[18,20,21]$. One of the key factors in this case is the benefit of increased organizational flexibility: "The documentation, improvement and automation of these processes as a result of various competitive and regulatory pressures should lessen the internal rigidity of organizations. Processes also serve as the link between an organization and its business partners. To the extent that interorganizational processes are improved, documented and automated, one would expect that the ability of the firm to interact flexibly in its environment should be improved"[3].

\subsection{IT-Enabled Process Innovation}

As IT becomes ubiquitous in society and companies it is inherently important for processes as well. In some environments process innovation relies on the potential to adapt within the underlying IT infrastructure. IT systems and infrastructure therefore need to be designed in such a way that it enhances an organisation's capability to innovate. Any process innovation effort needs to take into account the IT infrastructure 
it impacts as a factor that could either enable or hamper the chances to succeed. Mitchell and Zmud [22] incorporate under IT infrastructure all "enabling technologies, sourcing arrangements, and policies that form an intricate system of informationrelated activities." Getting a hold of such a system is quite difficult if its parts are scattered over a multitude of both internal and external parties. Each particular element could potentially make or break redesign efforts. So therefore, when the opportunity arises IT infrastructure should be designed in such a way that they enable rather than obstruct process innovation. Designing a robust business process goes often hand in hand with reviewing and redesigning major parts of the IT infrastructure which in itself can be an innovation [22]. In the SPOMS case the IT presence was undeniable and obviously the former IT infrastructure was not at all enabling innovation, rather the opposite. Therefore the IT department was involved early on leading to a solution that was not only supported but also driven by multiple departments - including IT - where all involved parties acknowledged that the IT infrastructure to be developed had to be not only efficient in the short term but also enabling growth and innovation in the long term. The infrastructure has thus become a dynamic capability [23] for Belgacom Mobile, allowing them to adapt to future market requirements.

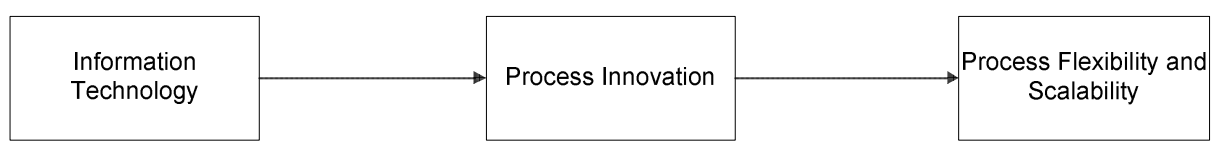

Fig. 1. IT-enabled process innovation (adapted from Davenport, 1993)

Investing in IT backbone systems has a positive impact on the process innovation capability. Research by Kim and Kim [24] has shown that investing in IT to deal with dynamic business markets provides a competitive advantage through enhancing a firm's ability to innovate internal processes. Organisations that are able to adapt processes flexibly to changing environments hold an advantage over their less flexible competitors. These insights correspond with the statements by Stohr and zür Mühlen [3] that process flexibility allows organisations to "rapidly assume new competitive positions and to act proactively to achieve competitive advantage". A combination of optimised processes and smart supporting IT systems should result in opportunities to innovate service and product delivery, and to compete in fast changing environments. Process flexibility can help an organisation to deliver new products or services to the market as fast as possible and to react swiftly on market changes [3].

According to Davenport [17] IT has an impact on process innovation in several ways. IT brings opportunities to eliminate human labour from a process, to capture process information to better understand the process, to change the sequence of the process or enable parallel activities, to track the status of the process, to improve process analysis and decision making, to coordinate a complex process, to coordinate between tasks and processes, to capture and distribute knowledge and, finally, to eliminate intermediaries from the process. Many of these opportunities are supported by the SPOMS case. 


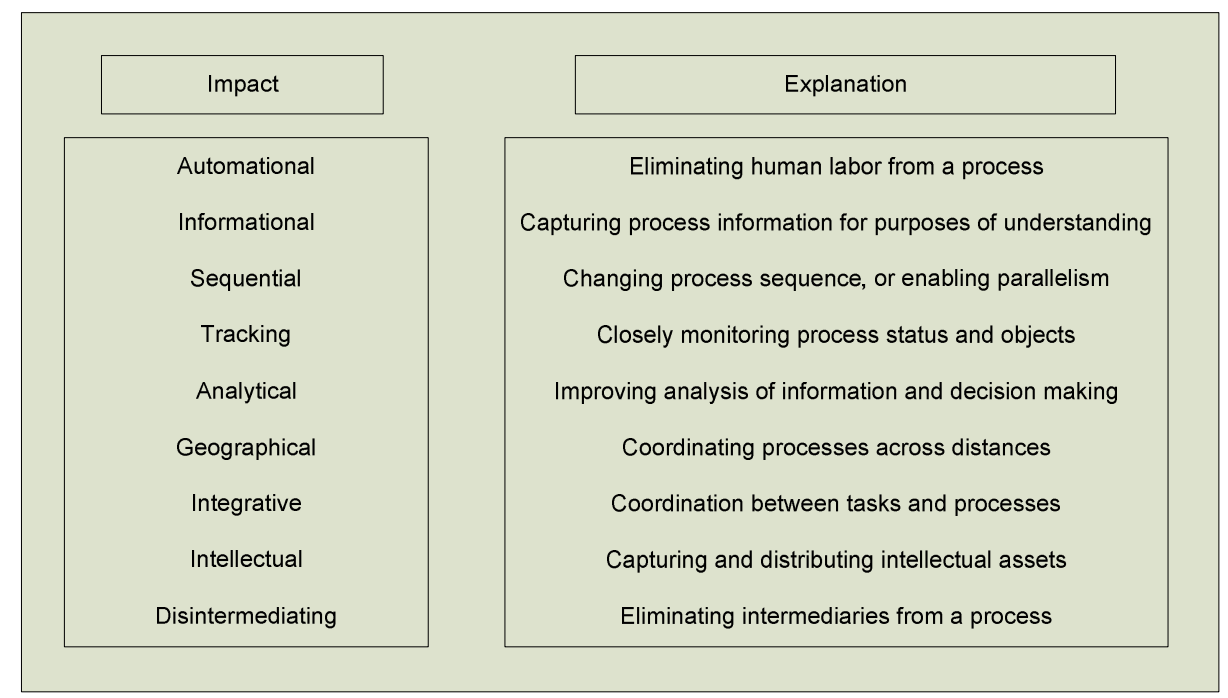

Fig. 2. IT impact on process innovation (adapted from Davenport, 1993)

On the other hand Davenport [17] admits that IT can be a constraint for process efficiency and innovation. The SPOMS case shows that, if IT systems become too complex for example, they pose a barrier for the performance of the process. The SPOMS IT systems landscape is very complex and dispersed. It is often difficult, expensive and time-consuming to replace all legacy systems by a new one but that can be dealt with in an elegant way by opting for an architectural approach where the process is supported by an orchestrating instance (in this case the SPOMS dashboard) communicating with existing legacy systems and using them as a service.

Apart from technological conditions, a number of other conditions needs to be in place. Business processes are unlikely to be efficient and/or flexible if there is no clearly defined ownership, if the processes are not transparent, etc. A typical symptomatic problem, especially in larger organisations, is that all subsystems - i.e. departments, geographic regions, business units - act as islands in the organisation although they are supposed to function as one system. The issue gets even more of a barrier if business processes involve many $3^{\text {rd }}$ party interventions, as in the SPOMS case [25]. Ever since large organisations have existed specialisation and integration have to be balanced. Working on process innovation should start from there. Process innovation efforts should not focus on mere automations of processes but on clarifying activities and roles and organising and optimising the allocation and execution of those. Hence, process innovation projects are both organisational adaptations and an IT infrastructure supporting that particular business process [22].

\section{IT-Enabled Process Innovation at Work: SPOMS}

For Belgacom Mobile, flexible and efficient core processes are a strategic objective. In order to be effective, a redesign effort should reconsider process activities and 
resources, and how they are conceived, planned and implemented [26]. Davenport [17] categorizes redesign projects as process innovations "when they produce radically new configurations of assets and activities". If the innovation effort is characterized by a high degree of information technology (IT) involvement, it is described as 'IT-enabled innovation'.

In the SPOMS case, the need to drastically innovate the process and its underlying IT system was obvious. The burning platform for initiating the project was the imminent risk of a system breakdown, with considerable consequences for the entire ordering process and hence for the overall position of Belgacom Mobile in a highly competitive market with mobile customers. Given the evident need, the project could be approached simultaneously as an opportunity to make the SIM card future-proof, thanks to a flexible and scalable design. Business processes in an environment such as the business environment in which Belgacom Mobile operates, with a multitude of supporting IT systems, are highly interdependent. In such circumstances "IT alters the ways in which people work and execute business processes, both within the enterprise and with business partners and customers"[14]. As far as Belgacom is concerned, IT investments serve three purposes, which indicate the intended benefits accruing from IT: firstly, IT is an enabler for running the business (enabler); next, IT can help to grow the business (scalability); and lastly, IT has the ability to transform the business (flexibility). The SPOMS case could be regarded as an investment supporting each of these purposes.

Table 1. Three IT purposes at Belgacom (Source: Presentation by Mr Scott Alcott, Executive VP Operations, Belgacom Group, 22/02/2010, [27])

\begin{tabular}{|c|l|}
\hline \multirow{3}{*}{ Short- } & $\begin{array}{l}\text { Run the business: An indicator of how much of the IT resource is } \\
\text { consumed and focused on the continuing operation of the business. } \\
\text { This largely covers maintenance, renewal, and capacity-related } \\
\text { expenditure. }\end{array}$ \\
\cline { 2 - 3 } term & $\begin{array}{l}\text { Grow the business: An indicator of how much of the IT resource is } \\
\text { consumed and focused on developing and enhancing IT systems in } \\
\text { support of business growth (typically organic growth). New projects } \\
\text { are captured in this category. }\end{array}$ \\
\hline Mid- & $\begin{array}{l}\text { Transform the business: An indicator of how much of the IT } \\
\text { resource is consumed and focused on implementing technology } \\
\text { systems that support new business models, structurally reduce the } \\
\text { total cost of ownership and create sustained efficiencies. }\end{array}$ \\
\hline
\end{tabular}

\subsection{The SPOMS Project}

The SPOMS project scope included a myriad of processes, starting from master data creation in an ERP software module, up to the hand-over of the SIM card data to the Order Management System and IT integration domains, while incorporating many third parties outside Belgacom Mobile, such as SIM suppliers, product suppliers, 
logistics providers, Mobile Virtual Network Enablers (MVNEs) ${ }^{1}$ and Direct Mobile Virtual Network Operators (MVNOs) ${ }^{2}$. Together these processes constitute the supply chain process for ordering SIM cards at Belgacom Mobile.

The SIM card supply chain process at Belgacom Mobile, as it formerly existed, still involved a lot of manual operations. SCM administrators were responsible for monitoring the entire process, keeping a spreadsheet overview based on a purchase order number reference, generated by the ERP software. Next, they had to send out a spreadsheet file with procurement details to a number of third parties such as distributors, suppliers, and packagers, each requiring different types of files. Therefore they had to rework the response file to the proper layout and in most cases send this new file by e-mail to the addressee. Generating these files manually was a time-consuming practice, leaving ample room for errors. Depending on the SIM card type, the procurement process could also differ, which further complicated the followup of the entire process. Errors could easily go unnoticed and remain unreported. Moreover, each party involved in the process had different ways of communicating with Belgacom Mobile. The process for special commercial campaigns had a total lead time of 3 months (i.e. from start-up of the campaign until stock is available to launch on the market). Finally, the process capacity was a limiting factor for the sales volume of SIM cards by Belgacom Mobile.

The imminent danger of a failure in the complex tangle of applications and entities posed a real threat to the business continuity of Belgacom Mobile. Errors in this core process could severely damage Belgacom's reputation and brand image. The emergency of the situation prompted Belgacom Mobile to assign a 'MUST DO' label to the SPOMS project, meaning it had strategic value for the company and was high on the priority agenda. The IT department and the marketing department agreed from the start that reengineering of SPOMS was a necessity and lent their full support to this project. The Supply Chain Manager and the external agency that was hired to execute the project opted from the start for an architectural end-to-end approach. Therefore, an IT project architect was involved in the project team early on. With reference to the 'old' process, the Supply Chain Manager stressed the urgent need for radical change: "We are currently facing a serious risk of business continuity failure. At the time, the market was growing and customers were becoming more demanding in terms of lead time. Frankly, I do not think we would have been able to cope much longer. We simply could not scale, let alone be more flexible." The SIM card Product Manager, being the main internal customer of SPOMS, acknowledges this: "At the

\footnotetext{
${ }^{1}$ MVNE: Mobile Virtual Network Operators enable the activation of the SIM cards on the network. This party needs to receive the technical information through an electronic file. Belgacom Mobile performs the procurement of the SIM cards, but the MVNE activates the SIM cards on the network.

${ }^{2}$ MVNO: A Mobile Virtual Network Operator is a provider of SIM cards that actually uses Belgacom Mobile services to operate. These operators receive SIM cards with a specific design from the logistics provider through the SIM card ordering process, but they do not receive the SIM card data in an electronic format. They are called virtual as they do not operate themselves, but use Belgacom Mobile as provider while using their own branding.
} 
marketing side we were welcoming every attempt to considerably reduce the time-tomarket for card introductions.

The business case for the SPOMS project included the following objectives:

1. Integration of the many departments and business partners

2. Reducing manual operations

3. Standardization

4. Decreasing total lead time

5. Increasing production process capacity

The basis for the set-up of SPOMS was inspired by several theoretical principles. These principles served as a general guideline for successfully redesigning and automating the process.

- Making the solution flexible to allow for adaptation to future requirements and reuse of existing components using the principles of Service-Oriented Architecture (SOA), web services and objectoriented programming where possible.

- $\quad$ Centralized approach to process governance and ownership, using a dashboard to act as a 'process orchestrator'.

- Making the processes product independent, thus building a product factory, to allow flexibility in designing new products in the day-today product innovation at Belgacom Mobile.

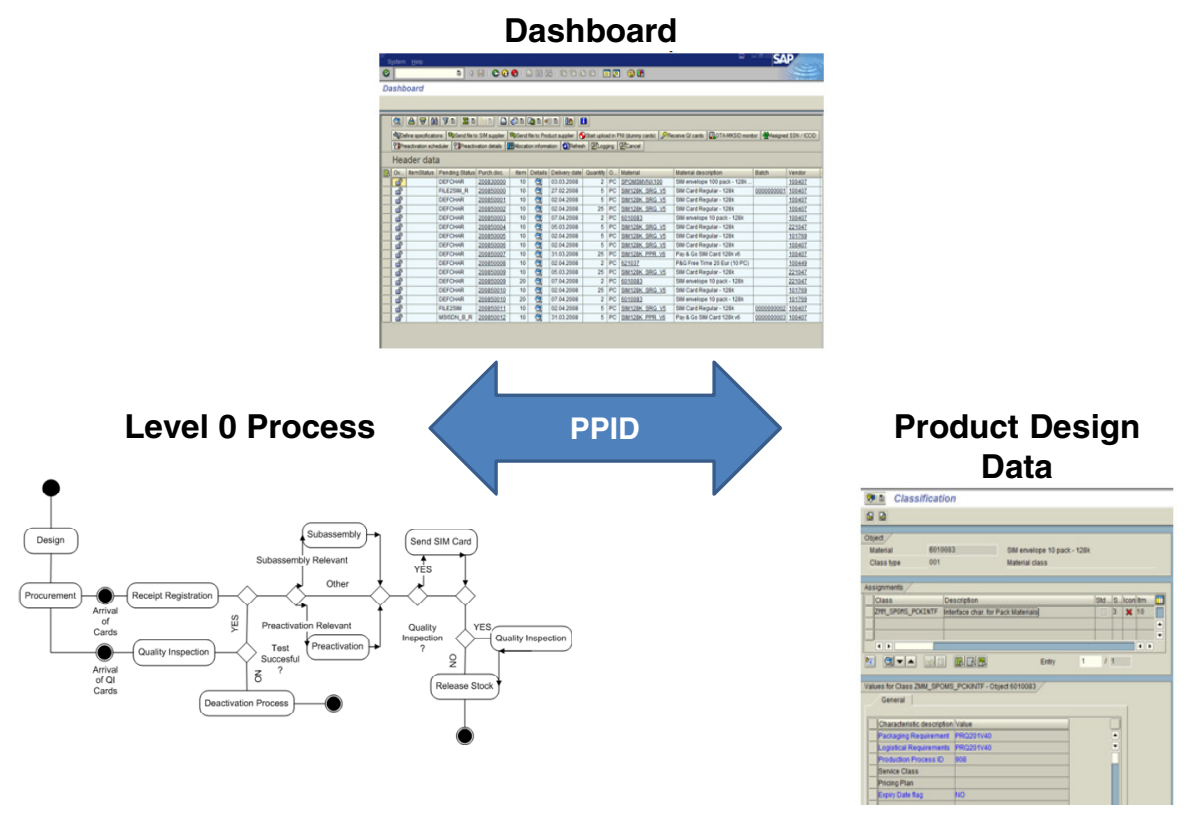

Fig. 3. Belgacom Mobile SIM card ordering process reengineering project overview 
The SPOMS project presents two new features that are being introduced as innovations to the former process: the creation of a level zero process map as a representation of the as-is situation of the SIM card ordering and activation process (see figure 3), and the creation of the SPOMS dashboard in order to provide the user with an overview of all current purchase orders in the process (see figure 3 ).

\subsection{An Architected Process Solution}

First of all, the as-is process was critically examined and completely redesigned. The newly developed process model was described at the highest level by a generic level zero process that can be applied to all existing SIM cards types and can easily be adapted when new SIM card types are being introduced. Using the level zero process contributed to simplifying the SIM card ordering process and capturing all necessary steps in the entire business flow, regardless of the type of SIM card. This enabled Belgacom Mobile to separate the processes from the products, thus increasing effectiveness and enabling the definition of new products with specific process flows.

The idea behind the SPOMS concept was to create one general flow - the so-called level zero process - that can be applied in all cases and to all production processes (see figure 4). Because not every step in the level zero process needed to be performed for all of the production processes, guidelines had to be developed to indicate what steps were relevant in which cases. These decision points are saved in production process templates. For each production process ID, the actions to be performed are identified beforehand. When a SIM card resource or SIM pack is defined as a material in the ERP software, a production process ID needs to be assigned to it. This enables SPOMS to decide which paths to follow when ordering these materials.

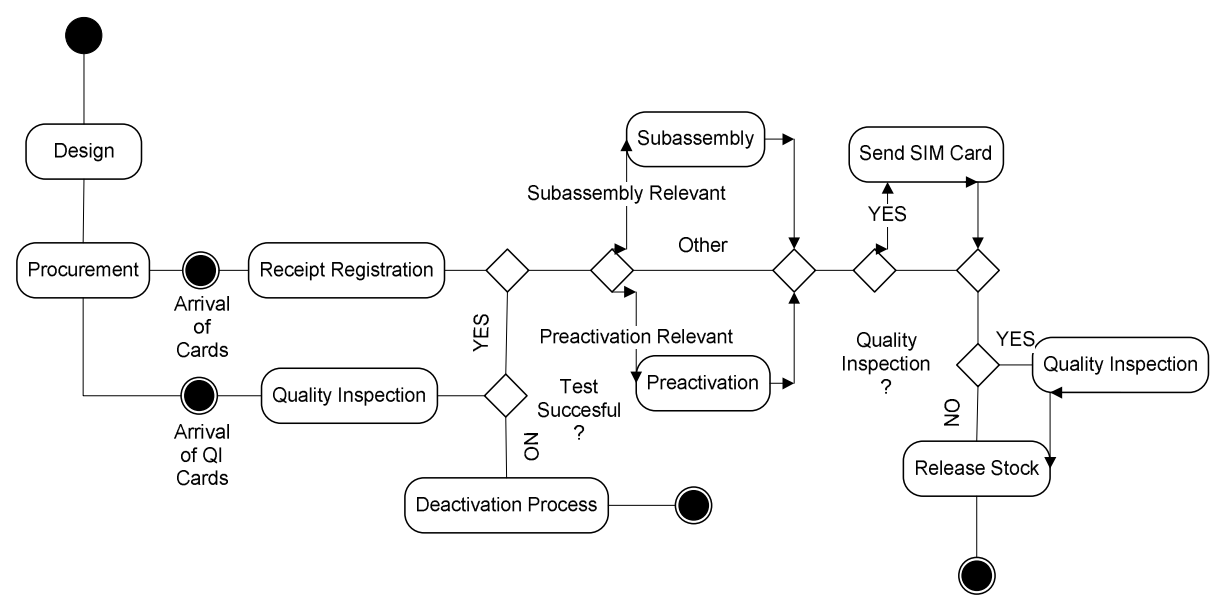

Fig. 4. The Level 0 Belgacom SIM card ordering process 
The Logistics Manager explains the new process as follows: "This new process is nothing like the old one. Before, we had no real overview of the status of orders for new cards, responsibilities were not centralized, and everyone seemed to be constantly working in fire-fighting mode. We managed to reengineer what used to be a very complex and burdensome business process with a lot of manual interventions to an almost fully automated, streamlined and transparent process that not only interconnects internal departments but also some external partners."

\subsection{Centralized Process Governance}

Secondly, the installation of a dashboard was an important project milestone. The purpose of the dashboard was to provide a single screen overview of all purchase orders currently in progress and to become the primary tool for steering the process. The dashboard would provide the tools for one-click generation of the input files for suppliers, starting the pre-activation scheduling, adding order-specific characteristics such as serial numbers, et cetera. Every step of the SIM card ordering process has been added as a status to the dashboard, which enables the user to view up-to-date and accurate status information for each purchase order item line.

The SPOMS dashboard is the core component of the SPOMS solution. It is the heart of SPOMS, from which most of the functionalities in the process can be accessed in an easy and intuitive way. The dashboard acts as a 'process orchestrator', and is the leading application triggering actions throughout the entire process by means of web services. The dashboard also keeps track of the status of interfaces and actions in the ERP system and in related internal and external systems. All interfaces that leave or enter SPOMS update the relevant dashboard statuses for the individual purchase order items.

The dashboard is the main tool for Logistics to perform the day-to-day follow-up of the SIM card procurement process, as it shows the status in ordering, production, quality testing and delivery of SIM cards and SIM products (or packs). The SPOMS dashboard was conceived as a native ERP transaction screen, retaining the same look and feel as the other ERP transactions.

The main purposes of the SPOMS dashboard can be summarized as follows:

- To be the main tool for the SIM card purchasing follow-up on a daily basis, visualizing the purchase order item status throughout the entire process.

- To be the orchestrator of the SIM card ordering process, triggering all the actions needed to complete the process.

Integrating the level zero process and the dashboard functionality, however, implied an optimisation of the current master data creation procedure. For each SIM card production process type (PPID), a template was prepared specifying the dashboard functionalities and statuses that are relevant for that particular template. For each newly developed SIM card, the template already defines which process steps the card will have to go through. Furthermore, the technical approach adopted for the SPOMS project assured that all the SIM card data formatting and mediation required by the 
level zero process to interface with other technical components of Belgacom Mobile and the various third parties, are performed correctly and in a secure way.

\subsection{Project Implementation Challenges}

Due to the complexity of the systems integration, the project presented multiple challenges. On the architectural level, two major challenges had to be addressed. First and foremost, data consistency had to be carefully safeguarded between all of the integrating systems. Secondly, all sub-processes needed to be aligned and the possibility to initiate, follow up and perform error handling had to be integrated. In order to cope with these challenges, the decision was made to adopt a process orchestration or centralized process approach, rather than a decentralized process approach. Process orchestration implies that the process is fully controlled and organized from one central location, and that every action/service reports back to the process controller. As shown in figure 1, for the SIM card ordering process, all actions are initiated and followed up in the SIM Card Ordering Dashboard, which acts as the process controller.

This orchestrated way of working for SPOMS provides the following advantages:

- A status overview in the ERP system was established showing the current process phase. Every process step taken in a different environment reports back to the controller dashboard as soon as that process step is completed or when an error occurs. This ensures that the processes are perfectly aligned as there is one central controller controlling the entire process.

- New actions can only be initiated from the controller dashboard. As a result decisions regarding the process flow to be followed can only be made from one central point, instead of having other systems performing consecutive actions and reporting back only after a number of actions have been completed.

- Errors are immediately reported to the controller, which allows commencing error handling in a virtually online mode.

"We in marketing are now completely responsible for the SIM card ordering management process," stresses the SIM card Product Manager. "Not only do we control the process input, we can also reconfigure it for new SIM card types. If anything, the innovated SPOMS process has put an end to the situation where the responsibility for errors was shunted back and forth between departments. With the SPOMS dashboard we can monitor the status of the outstanding orders in real time, and the system warns us immediately when there is a problem somewhere along the chain. Now, we can manage the entire process in a much more focused way."

\section{Accomplishments: IT-Enabled Innovation Rewarded}

The performance of the redesigned and automated process was reviewed in May 2009. Data gathered from January to April 2009 were compared with data collected 
over the same period in 2008. As the renewed SPOMS went live in October 2008, it was considered that enough time had elapsed to gain experience and further refine the process before starting the comparison. The old and new SPOMS were compared based on the following criteria:

\subsection{Increased SIM Card Production Capacity}

The total number of SIM cards introduced onto the market after creation of a purchase order, has remained the same. The reason for this can be found in the market demand, which has slowed down because of the economic crisis. Nonetheless, we note that the process capacity has increased substantially.

The architectural approach provides for flexible up- and downscaling without any hassle. Development of new applications is far easier in service-oriented environments because these allow for flexible reuse of service components (Weske, 2007).

\subsection{Shorter Lead Time from Purchase Order Creation Until Ready for Delivery to the Market}

The lead time of the entire production process was reduced significantly. For every 100,000 SIM cards produced, 23 working days have been gained, i.e. a lead time reduction of approximately 1 month per 100,000 cards. This time saving is the result of a reduction of the time needed to develop and send the SIM card production request file to the SIM supplier. In the redesigned SPOMS no manual intervention is needed to create the request file, as opposed to the former SPOMS.

The Supply Chain Administrator can now give priority to marketing actions if needed. In 2008, for every preactivation a ticket had to be created for requesting this preactivation and time-consuming communication was needed in order to update the schedule. This has now been automated and centralized at the level of the process owner, who makes the decisions and manages the entire process. Next to the process optimization by the scheduler, also the capacity of the preactivation system has increased.

\subsection{Shorter Total Lead Time of Marketing Actions, from Defining a New Card Layout Until Ready for Delivery to the Market}

Given the shorter production lead time (see above), the total lead time is also considerably reduced. When considering the total lead time of marketing actions, we note that in 2008 a marketing action was initiated 3 months before the planned deadline, whereas in 2009 an action could still be approved until 6 weeks before the scheduled date. The reasons for this are the shorter production lead time on one the hand (reduction of 1 month), and the faster definition of the card, which is now a transparent process that can be carried out by means of master data creation, on the other hand. 


\subsection{Reduction of Workload in the Supply Chain Department}

Within the supply chain team an $80 \%$ reduction of FTE involvement in SPOMS has been realized, allowing FTEs to be reallocated to other activities in the department. Furthermore, the automation of the entire process has also significantly reduced the workload in all other departments involved, because the process is far less complex and error-prone than before.

In general, due to the shorter total lead time, Belgacom Mobile can respond much faster to market demands for promotional actions, which benefits overall competitiveness. Secondly, the internal stress level, caused by barely being able to meet the deadlines of a marketing action, has dropped noticeably. This is mainly the result of the shorter total lead time, which allows for a better planning and faster goto-market, smoother communication between all parties and reduced manual followup of actions.

\section{$5 \quad$ Lessons Learned}

\subsection{Lesson 1: The Product Factory for Process Flexibility}

During the reengineering project, some important lessons were learned that may prove valuable for future process reengineering projects. First of all, a major breakthrough was realized by separating product and process by means of the Product Factory concept. The key benefit of this approach is long-term process flexibility, which allows for product innovation without consequently having to change the process or having to install a new process. The reusability of the solution concept for other applications is another added bonus that comes with the application of SOA.

\subsection{Lesson 2: Combining Process Thinking (BPM) and Architecture (SOA) for IT-Enabled Process Innovation}

Secondly, the SPOMS case at Belgacom clearly highlights the potential of a processoriented approach combined with architectural principles. The Logistics Manager comments: "This project has really convinced me of the importance of process thinking and architecting for this company. It was remarkable to see project participants ponder the impact of the decisions we made throughout the SPOMS project on other departments (even beyond the ones involved in the project) - which is quite unique. Some of this end-to-end thinking has led us to add additional peripheral processes to the original scope of the project." He adds: "Our choice for an architected approach has enabled us to unravel the enormous complexity of this business process. The investment in business process modeling has resulted in transparency, which helped us to make sure that we did not overlook any important aspects. The architectural approach we adopted provided the necessary scalability and flexibility. It did take almost a year to map all of the requirements, but this effort certainly paid off in terms of efficiency and sustainability." 


\subsection{Lesson 3: Project Management}

In terms of project management the project lived up to the expectations. The scope remained virtually unchanged during the entire project, and the project was completed on time and even on budget. Critical to this success were the well formulated business requirements, the strong business case, and great collaboration between all of the parties involved. As the project sponsor, the Logistics Manager made sure that the initial project scope and architecture were not compromised by superfluous 'nice-tohaves'. The SIM card Product Manager testifies to this: "Indeed, from a marketing perspective we tend to push for more features all the time. But the project sponsor was always there to challenge the necessity of these extras from the viewpoint of the initial business case and verified if they really fitted within the solution architecture. This resulted in a solution that is highly efficient, but can still be leveraged for future use." The IT Project Architect responsible for designing and implementing a solid technical solution, agrees: "This was one of these projects that was actually completed on time, on budget and without major scope adjustments. The fact that a sound business case and analysis were developed and carried out prior to the project launch really proved worthwhile. We knew why we were doing it and what we were getting ourselves into."

\section{Conclusion}

Over the years, Belgacom Mobile's market position has come under increasing pressure due to fierce competition and changing customer demands. As the Telco sector is highly turbulent and known for its fast technological advances, flexible people and processes are crucial for keeping up with the competition. For marketing purposes it is extremely important to be able to launch SIM card campaigns as quickly as possible. In addition, the risk of process failure may affect Belgacom Mobile's brand image and market position. The SIM card order management process is therefore a core process for Belgacom Mobile and its reliable functioning is therefore an asset to the company as a whole.

The Logistics Manager sums up the achievements of the SPOMS project: "We have put a lot of hard work in SPOMS. We have prepared exceptionally well with a very strong team of people combining different backgrounds. The result is a truly versatile and solid new business process supported by tools that enable the front-line staff to provide the efficiency and flexibility our markets require. This IT-enabled business process innovation is actually the result of a combination of end-to-end thinking, team work, results orientation and, last but not least, an architectural approach to support not just sustainability of a technical solution but also design freedom for product managers."

This paper contributes to the general understanding of combining an architectural approach with BPM in the frame of IT-enabled improvement projects. Managers gain a deeper insight into how process reengineering can enhance process flexibility and thus create room for product innovation generating benefits that go beyond mere internal efficiency gains. In general, due to the reduced total lead time, Belgacom Mobile can 
respond more quickly to market demands for promotional actions. This has strengthened the company's competitive position. In terms of project management, the SPOMS project stands out because it was completed on time and on budget, without major scope adjustments. Moreover, project insiders indicated a close collaboration between several business departments and the IT department as a key factor to the project's success. Ultimately, the new SPOMS process promises to deliver not only operational benefits, but also maximum process flexibility for new products to be introduced, which is one of the main drivers in the turbulent telecommunications sector. Furthermore, this case provides evidence of the business value of IT-enabled process innovation and BPM investments, a missing link in literature.

Acknowledgements. The authors wish to thank Belgacom Mobile executives Johan Verbeeck, Pascal Masuit, John-David Hendrickx, Scott Alcott and Laurent Claus for their valuable contributions to this work and for the possibility to look into this exceptional case. Furthermore we express our gratitude to Bert Van Genechten, a Delaware consultant.

\section{References}

1. Becker, J., Kugeler, M., Rosemann, M.: Process Management: A Guide for the Design of Business Processes. Springer, Berlin (2004)

2. Weske, M.: Business Process Management: Concepts, Languages, Architectures. Springer, Heidelberg (2007)

3. zür Muehlen, M., Stohr, E.A.: Business Process Management: Impact on Organizational Flexibility. Global Journal of Flexible Systems Management 9(4), iii-v (2008)

4. Beimborn, D., Nils, J., Weitzel, T.: Drivers and Inhibitors of SOA Business Value Conceptualizing a Research Model. In: Proceedings of the Fourteenth Americas Conference on Information Systems, Toronto, Canada (August 2008)

5. Trkman, P., Kovačič, A., Popovič, A.: SOA Adoption Phases: A Case Study. Business \& Information Systems Engineering 3(4), 211-220 (2011)

6. Behara, G.K.: BPM and SOA: a strategic alliance. BP Trends (May 2006)

7. Carter, S.: The role of Business Process Management in SOA. DM Review 17(5) (2007)

8. Malinverno, P., Hill, J.B.: BPM and SOA are better together. Gartner Research Report (2007)

9. Walker, L.: IBM business transformation enabled by service-oriented architecture. IBM Systems Journal 46(4), 651-667 (2007)

10. Brahe, S.: BPM on Top of SOA: Experiences from the Financial Industry. In: Alonso, G., Dadam, P., Rosemann, M. (eds.) BPM 2007. LNCS, vol. 4714, pp. 96-111. Springer, Heidelberg (2007)

11. Conlon, S.J., Hale, J.G., Lukose, S., Strong, J.: Information Extraction Agents For Service Oriented Architecture Using Web Service Systems: A Framework. Journal of Computer Information Systems 48(3), 74-83 (2008)

12. Sidorova, A., Isik, O.: Business process research: a cross-disciplinary review. Business Process Management Journal 16(4), 566-597 (2010)

13. Becker, A., Widjaja, T., Buxmann, P.: Value Potentials and Challenges of ServiceOriented Architectures. Business \& Information Systems Engineering 3(4), 199-210 (2011) 
14. El Sawy, O.A., Pavlou, P.A.: IT-Enabled Business Capabilities for Turbulent Environments. MIS Quarterly Executive 7(3), 139-150 (2008)

15. Bell, A.E.: From the Front Lines DOA with SOA. Communications of the ACM 51(10), 27-28 (2008)

16. Baskerville, R., Cavallari, M., Hjort-Madsen, K., Pries-Heje, J., Sorrentino, M., Virili, F.: Extensible Architectures: The Strategic Value of Service-Oriented Architecture in Banking. In: Proceedings of the 13th European Conference on Information Systems, Regensburg, Germany (2005)

17. Davenport, T.H.: Process Innovation: Re-engineering Work Through Information Technology. Harvard Business School Press, Boston (1993)

18. Zairi, M.: Business process management: a boundaryless approach to modern competitiveness. Business Process Management Journal 3(1), 64-80 (1997)

19. Harmon, P.: Business Process Change: A guide for business managers and BPM and Six Sigma professionals, 2nd edn. MK Publishers (2007)

20. Lee, R.G., Dale, B.G.: Business Process Management: a review and evaluation. Business Process Management Journal 4(3), 214-225 (1998)

21. Hammer, M., Champy, J.: Reengineering the corporation, 1st edn. Harper Business, New York (1993)

22. Mitchell, V.L., Zmud, R.W.: The effects of coupling IT and work process strategies in redesign projects. Organization Science 10, 424-438 (1999)

23. Eisenhardt, K., Martin, J.: Dynamic Capabilities: what are they? Strategic Management Journal 21(10/11), 1105-1121 (2000)

24. Kim, J.W., Kim, E.W.: The Impacts of IT Investment Directions and Strategies of Supply Chain Management Implementing Enterprises on Business Performance. International Journal of Business Research 9(4), 126-137 (2009)

25. Lawrence, P.R., Lorsch, J.W.: Differentiation and Integration in Complex Organizations. Administrative Science Quarterly 12(1), 1-47 (1967)

26. Damanpour, F.: Organizational innovation: a meta-analysis of effects of determinants and moderators. Academy of Management Journal 34(3), 555-590 (1991)

27. Alcott, S.: Presentation by Mr. Scott Alcott, Executive VP Operations. Belgacom Group, at a 'We Invite for You' session (February 22, 2010) 